\title{
Prediction of auto-ignition temperatures and delays for gas turbine applications
}

\author{
Roda Bounaceur, Pierre-Alexandre Glaude, Baptiste Sirjean, René Fournet, \\ LRGP CNRS, Université de Lorraine \\ 1, rue Grandville - BP 20451 - 54001 Nancy, France \\ Pierre Montagne, Matthieu Vierling, \\ GE Energy Product-Europe, \\ 20 avenue de Maréchal Juin, BP 379, 90007 Belfort, France \\ Michel Molière \\ IRTES-LERMPS - Université de Technologie de Belfort Montbéliard \\ 90010 Belfort Cedex, France
}

\begin{abstract}
Gas turbines burn a large variety of gaseous fuels under elevated pressure and temperature conditions. During transient operations like maintenance, start-ups or fuel transfers, variable gas/air mixtures are involved in the gas piping system. Therefore, in order to predict the risk of auto-ignition events and ensure a safe and optimal operation of gas turbines, it is of the essence to know the lowest temperature at which spontaneous ignition of fuels may happen. Experimental autoignition data of hydrocarbon-air mixtures at elevated pressures are scarce and often not applicable in specific industrial conditions. AIT data correspond to temperature ranges in which fuels display an incipient reactivity, with time scales amounting in seconds or even in minutes instead of milliseconds in flames. In these conditions, the critical reactions are most often different from the ones governing the reactivity in a flame or in high temperature ignition. Some of the critical paths for AIT, especially those involving peroxy radicals, are similar to those encountered in slow oxidation. Therefore, the main available kinetic models that have been developed for fast combustion, are unfortunately unable to represent properly these low temperature processes.

In this context, a numerical approach addressing the influence of process conditions on the minimum auto-ignition temperature of different fuel/air mixtures has been developed. For that purpose, several chemical models available in the literature have been tested, in order to identify the most robust ones. Based on previous works of our group, a model covering a large temperature range has been developed, which offers a fair reconciliation between experimental and calculated AIT data through a wide range of fuel compositions. This model has been validated against experimental auto-ignition delay times (AID) corresponding to high temperature in order to ensure its relevance not only for AIT aspects but also for the reactivity of gaseous fuels over the wide range of gas turbine operation
\end{abstract}

conditions. In addition, the AITs of methane, of pure light alkanes and of various blends representative of several natural gas and process-derived fuels were extensively covered. In particular, among alternative gas turbine fuels, hydrogen-rich gases are called to play an increasing part in the future so that their ignition characteristics have been addressed with particular care. Natural gas enriched with hydrogen, and different $\mathrm{CO} / \mathrm{H}_{2}$ syngas fuels originating from a blast furnace (BFG) have namely been studied. Globally, the individual species covered are: $\mathrm{H}_{2}, \mathrm{CO}, \mathrm{CO}_{2}, \mathrm{~N}_{2}, \mathrm{CH}_{4}, \mathrm{C}_{2} \mathrm{H}_{6}, \mathrm{C}_{3} \mathrm{H}_{8}, \mathrm{C}_{4} \mathrm{H}_{10}$, and $\mathrm{C}_{5} \mathrm{H}_{12}$. AIT values have been evaluated in function of the equivalence ratio and pressure. All the results obtained have been fitted by means of a practical mathematical expression. The overall study leads to a simple correlation of AIT versus equivalence ratio/pressure that may be of fruitful use for the engineering community.

\section{INTRODUCTION}

Among alternative fuels to natural gas, process gases, syngases and hydrogen-containing gases can find an increasing place as gas turbine fuels in the future. However most of them entail higher explosion risks than methane, namely in the event of a leak or during purges of pipes if air is used. More generally, many chemical processes use flammable gases and vapors under elevated pressures and high temperatures. The evaluation of auto-ignition hazards and safety concerns for a safe operation of such processes requires a sufficient knowledge of the lowest temperature at which spontaneous ignitions can take place. The Auto-Ignition Temperature data (AITs) found in the literature are usually determined by applying standardized test methods that are based on small vessels and are performed at atmospheric pressure. However, AITs are not fixed data but largely depend on the equivalence ratio, the pressure as well as the volume since convective transport can influence the tests. Therefore, the AIT values 
measured at atmospheric pressure and lab scale are often not applicable in industrial environments.

The auto-ignition of a gas mixture is a complex phenomenon that is influenced by many factors, which can be classified into three categories: (i) "intrinsic parameters" that are linked to the gas mixture itself (nature and concentration of the reagents, pressure, presence of additives, nature of the oxidizer...) ; (ii) "extrinsic parameters" which are dependent on the test apparatus (volume of the vessel, nature of the wall, flow motion...), and (iii) parameters linked to the method of detection of the ignition (auto-ignition criterion).

As a first observation, the auto-ignition temperature is strongly dependent on the nature of the fuel. As can be seen in Table 1, the AIT of hydrocarbon/air mixtures decreases with increasing molecular weight and chain length [1]. The AIT is also higher for branched hydrocarbons than for linear hydrocarbons. Some attempts were done to correlate the AITs of pure hydrocarbons with the average carbon chain length [2].

Table 1. Minimum auto-ignition temperature (AIT) of fuels at standard temperature and pressure in the literature $(\mathrm{K})$

\begin{tabular}{ccccc}
\hline Fuel & \multicolumn{4}{c}{ Reference publication } \\
& {$[1]$} & {$[2]$} & {$[3]$} & {$[4]$} \\
\hline Hydrogen & 810 & 845 & 845 & 833 \\
Methane & 868 & 810 & 905 & 858 \\
Ethane & 788 & 745 & 745 & 788 \\
Propane & 743 & 739 & 766 & 743 \\
$i$-Butane & 733 & - & - & 733 \\
$n$-Butane & 638 & 688 & 678 & 703 \\
$n$-Pentane & 533 & 557 & 505 & - \\
$n$-Hexane & 503 & - & - & - \\
\hline
\end{tabular}

Many experimental data have been recorded for individual fuel species, such as hydrogen [5], methane [6][7][8][9][10][11], ethane[6][12], propane [7][13], $n$-butane [14][15], or blends that are representative of natural gas [7] or LPG [11]. Usually, the lowest auto-ignition temperature is not reached under the stoichiometric conditions, but for richer mixtures i.e. between the stoichiometric concentration and the upper flammability limit [16]. Methane/air mixtures represent an exception to this rule: the lowest AIT of methane/air mixtures under 1 bar is reached in the lean range of 3.0-8.0 mole $\%$ of $\mathrm{CH}_{4}(0.3 \leq \phi \leq$ 0.8 ), while the stoichiometric concentration is to 9.5 mole $\%$ of $\mathrm{CH}_{4}$ [7]. In the same conditions, the minimum is reached at $\phi=4$ (15\%mol.) for a propane/air mixture. An increase in pressure generally decreases the auto-ignition temperature of a gas mixture [6]. Note worthily, while many processes in the chemical industry are conducted at elevated pressure, experimental data are mainly obtained under atmospheric conditions. It has been shown that a larger experimental vessel can lead to lower AITs [6], because of a decrease of the ratio between the heat exchanged at the walls and the heat of reaction released in the volume. The nature of the walls is also of importance since the material can give rise to chemical reactions (creation or destruction of free radicals) or develop a physical effect (source or sink of heat, adsorption of intermediates etc.). Wall treatments of the vessel have shown a strong influence on the AITs [9].

The most commonly used auto-ignition criterion is the visual observation of a flame but this method is applicable only to visible flames, require a test setup with a visual access and works in absence excessive soot. The visualization is more difficult at high pressure. Other methods rely on temperature or pressure recordings or the analysis of the reaction products that can replace the visual criterion, but the choice of the particular value of temperature or pressure rise may have a strong impact on the resulting AIT. For instance, a change of the temperature rise criterion from $50 \mathrm{~K}$ to $200 \mathrm{~K}$ can have a critical effect on the auto-ignition limit. The multiplicity of the factors influencing the AIT makes it difficult to elaborate a standardized determination method. A large number of standards actually exist e.g.: EN 14522 [17], DIN 51794 [18], ASTM E 659-78 [19], ASTM D2155-66 [20]. ASTM D288395 applies to the auto-ignition temperature of liquids and solids at high pressure, but is unfortunately unsuitable for gases. Consequently many teams use the experimental setup that is the most adapted to their specific applications. As a matter of fact, the auto-ignition temperature of methane determined by different test methods over the last thirty years has known a variation between $813 \mathrm{~K}$ and $923 \mathrm{~K}$ [11]. Besides hardware aspects, a number of experimental techniques exist for the generation of the auto ignition event, such as: closed vessels, rapid compression machines, shock tubes or continuous flow reactors. This wide panel of techniques is useful to cover the determination of auto-ignition delay times over large ranges of temperature, pressure and time scales.

Considering the complexity of this important topic, the team has decided to approach the auto-ignition properties at elevated pressures by means of comprehensive detailed kinetic models. The objective has been the assessment of the auto-ignition temperatures (AIT) and auto-ignition delay times of a wide range of fuels including hydrogen and covering namely natural gas, LPG and syngas. In overall, the gaseous species covered are the following ones: $\mathrm{H}_{2}, \mathrm{CO}, \mathrm{CH}_{4}$, light alkanes up to $\mathrm{C}_{5}$ and inert gases such as $\mathrm{N}_{2}$ and $\mathrm{CO}_{2}$. After assessing different kinetic models available in the literature against experimental data also taken from the literature, the auto-ignition properties of several fuels and air mixtures have been extensively evaluated in function of pressure and equivalence ratio using the best performing model.

\section{KINETIC MODELING}

Several comprehensive kinetic models for the oxidation and the combustion of light hydrocarbons have been proposed in the literature. However, most of these mechanisms have been designed for burner or engine conditions and are valid only for high temperature combustion $(>1000 \mathrm{~K})$, while kinetic data and mechanisms in the low temperature region are scarce. Flame conditions are far from auto ignition conditions in which the reactivity is very low and specific reactions that can be neglected at higher temperature may become critical paths. Flames have typical timescales much shorter (e.g. milliseconds instead of minutes) than auto-ignition processes where the chemistry of the oxidation may be an intermediate between those involved in a flame and during the degradation in the atmosphere. The formation of peroxy free radicals through the 
oxidation by oxygen of alkyl radicals coming from the fuel represents critical steps since they yield hydroperoxides, which are the branching agents responsible for the auto acceleration of the reaction. The oxidation of hydrocarbons at low temperature follows a general scheme summarized by the following reactions:

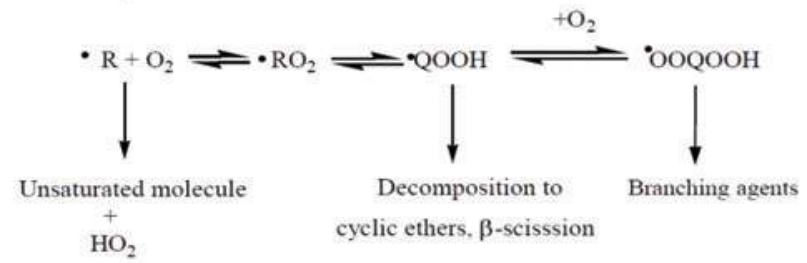

In the case of light fuel species such as methane and ethane, important intermediates are methylperoxy $\mathrm{CH}_{3} \mathrm{OO}$ and ethylperoxy $\mathrm{C}_{2} \mathrm{H}_{5} \mathrm{OO}$ radicals, which react in bimolecular reactions to produce the branching agents $\mathrm{CH}_{3} \mathrm{OOH}$ and $\mathrm{C}_{2} \mathrm{H}_{5} \mathrm{OOH}$. Many models miss some of these reactions that are negligible at higher temperature but are essential to correctly simulate AITs.

Among the models available in the literature, a popular one is GRI-mech [21] that has been optimized for the combustion of methane at high temperature. Another comprehensive mechanism devoted to the combustion of methane has been proposed by the University of Leeds [22]. The combustion of natural gas, as a mixture of light hydrocarbons, is the subject of GDF-Kin [23] and Konnov's model [24], which have been regularly up-dated. Some models for the combustion of light alkanes up to $n$-butane have been developed in LLNL that includes low temperature chemistry [25] or have been validated over a wide range of pressure and equivalence ratio (NUIG [26]). All these models have been validated against experimental ignition delay times, but at temperatures much higher than AIT.

A specific model, LRGP2014, has been created by our group based on own reaction bases and using the software EXGAS, which is an automatic mechanism generation tool [27]. This software developed in Nancy for several years allows the automatic generation of mechanisms for the gas-phase oxidation of hydrocarbons. It provides reaction mechanisms composed of three parts. A comprehensive primary mechanism contains only the reactions of the initial organic compounds, here propane, $n$-butane and $n$-pentane, and oxygen. The additions of alkyl radicals to oxygen molecules and the subsequent reactions leading to the formation of oxygenated compounds such as peroxides, aldehydes, ketones, and cyclic ethers, which are important below $1000 \mathrm{~K}$, are considered to properly predict the low temperature chemistry. A comprehensive $\mathrm{C}_{0}-\mathrm{C}_{2}$ reaction base includes all the reactions involving radicals or molecules containing less than three carbon atoms [28]. Reactions of methane, ethane, hydrogen and $\mathrm{CO}$ are included in this base. A lumped secondary mechanism contains the reactions consuming the molecular products of the primary mechanism (e.g ketohydroperoxides, alkenes, cyclic ethers, aldehydes, ketones), which do not react in the reaction base. Thermochemical data for molecules or radicals are automatically calculated based on group additivity methods. Kinetic data are estimated either based on thermochemical kinetics methods, or on quantitative structurereactivity relationships obtained from literature reviews. This system has been used to generate validated mechanisms for the low temperature oxidation of $n$-butane, isomers of pentane, $n$ heptane and iso-octane and large alkanes [27][29][30]. An extension of this system has also been achieved to model the oxidation of ethers and methyl esters using a comprehensive low temperature mechanism [31]. The final mechanism contains 209 species that are involved in 1473 reactions. The LRGP2014 model can be obtained upon request.

In the present work, the performances of these mechanisms were checked against some typical experimental results from the literature. Simulations were performed using the CHEMKIN II software [32] developed for the resolution of the mass and energy equations relevant to main laboratory reactors. In particular SENKIN, which is dedicated to the simulation of internal combustion engines, was used for the calculation of ignition delay times and the determination of AITs. AITs have been calculated by mimicking the Standard ASTM E 659-78 which considers that there is auto-ignition if a flame can be observed before a delay of 10 minutes after the load of the reagents in a $500 \mathrm{~cm}^{3}$ silica glass cylinder. In the calculations, auto-ignition was assumed to have occurred when a $400 \mathrm{~K}$ increase of the temperature was reached. Calculations assume a constant volume and a typical heat loss rate through glass walls $\left(\mathrm{h}=19 \mathrm{~W} \mathrm{~m}^{2} \mathrm{~K}^{-1}\right)$ [33]. It is important to stress the fact that this simple 0D simulation method does not capture the great complexity of the heat and convective mass transfer processes inside the test cylinder during real auto-ignition experiments.

\section{VALIDATION OF THE MODEL}

AITs of methane, ethane, and propane/air mixtures in function of the equivalent ratio were calculated at 1 bar using the seven different models that have been presented above and are reviewed below. The experimental decrease of the minimum AIT with the increasing chain length in hydrocarbons, shown in Table 1, is not reproduced by three of these models (GRImech [21], Leeds [22], and NUIG [26]) which predict higher AIT for ethane than for methane. Indeed, these models were developed for conditions much different from those that prevail in AIT. In fact they do not contain any reactions involving ethylperoxy and propylperoxy radicals needed to reproduce the low temperature reactivity of the parent fuels. As far as the others models are concerned, they account for the difference of reactivity between $\mathrm{C}_{1}, \mathrm{C}_{2}$ and $\mathrm{C}_{3}$ species even though large discrepancies exist between the different mechanisms. Once again, the lack of low temperature reactions in some of these models can explain these differences. The variation of AIT in function of pressure and equivalence ratio for different fuel/air mixtures was also investigated. An inversion between the AITs of methane and ethane calculated with the model of Konnov [24] was observed. This latter was then discarded in the next phase of the study.

With the three remaining models, minimum AITs at 1 bar were calculated for equivalent ratio ranging from 0.1 to 15 and compared with the CHEMSAFE data [1]. Figure 1 shows this comparison. The LLNL model [25] leads to AIT of $n$-butane higher than that of propane, in contradiction with the real trend. 
GdF-Kin [23] yields an AIT of $n$-pentane equivalent to that of $n$-butane. In fact, both of these models have been validated at low temperature for compounds up to $\mathrm{C}_{3}$ but none of them contains a complete low temperature mechanism for $\mathrm{C}_{4}$ and $\mathrm{C}_{5}$ species. In conclusion, it appears that, among all the compared models, only the LRGP2014 model proves robust enough to correctly reproduce the AIT dependence on the various operating conditions. Therefore, in the next phase of the study, which is set out below, this model was further tested against extensive literature data.

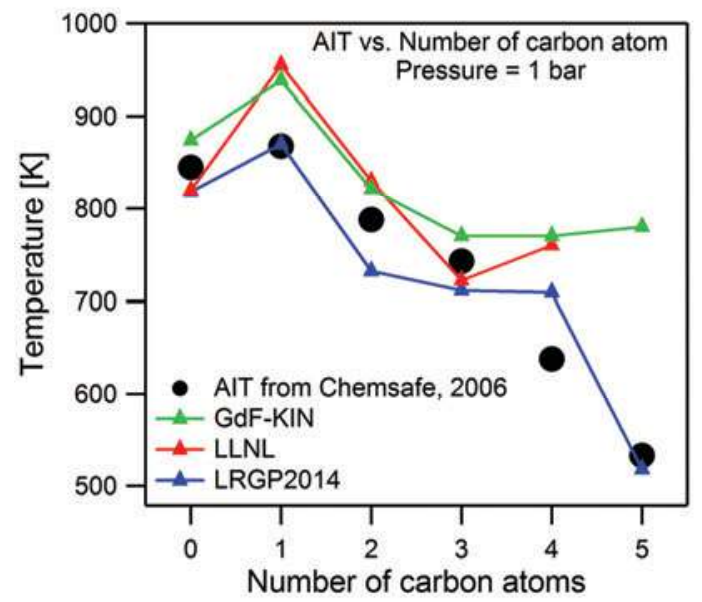

Figure 1: Minimum auto-ignition temperature vs. number of carbon atoms for different fuel/air mixtures at 1 bar.

Steinle and Franck [6] studied the oxidation of methane/air mixtures at very high pressure in cylindrical and spherical vessels. The comparison between simulated results and experimental data is visible in Figure 2a, showing a correct agreement. Caron et al. [10] and Norman [11] investigated several methane/air mixtures at different pressures and concentrations in a spherical vessel. Figure $2 \mathrm{~b}$ shows the pressure/temperature region obtained for a mole fraction of methane equaling $60 \%$ in air, corresponding to an equivalence ratio of 14.29. A fair agreement between experimental data and simulations is obtained, especially keeping in mind that the experimental uncertainties in AIT measurements are tens of Kelvins, as discussed above.

Experimental AITs of ethane, propane, $n$-butane and n-pentane have also been simulated with the LRGP2014 model. Figure 3 illustrates the evolution of AITs of propane and n-butane as a function of pressure. The model reproduces fairly well the trend of the AITs of propane (Figure 3a) measured in a 1 liter ignition vessel up to 20 bar [7]. The AITs of n-butane/air mixtures measured in a $8 \mathrm{~L}$ spherical bomb [14] are also well reproduced up to 25 bar (Figure $3 \mathrm{~b}$ ). In that case, it appears that AITs are not very sensitive to the pressure.
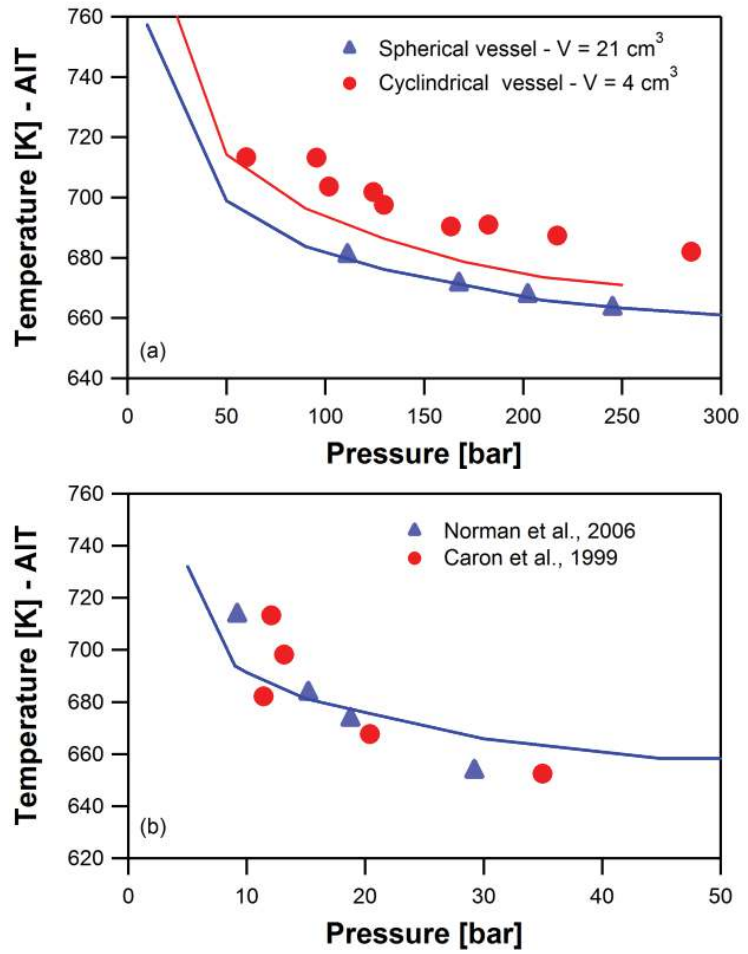

Figure 2: AIT of methane/air mixture as a function of pressure (a) equivalence ratio 2 , (b) equivalence ratio 14.3. Points are experimental data, lines simulations.

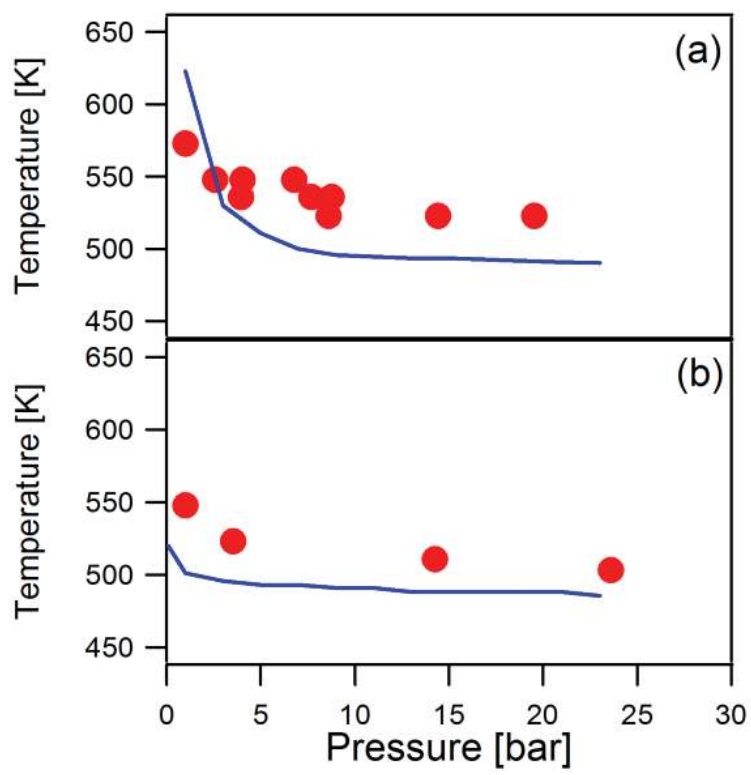

Figure 3: AIT of (a) propane/air and (b) $n$-butane/air mixture as a function of pressure. Points are experimental data, lines simulations. 
The behavior of gas mixtures is of most interest in real applications. Kong et al. [7] have studied the auto-ignition of methane/propane/air mixtures in a 1 liter ignition bomb. Figure 4 compares experiments and simulations for different equivalence ratios. Both trends and orders of magnitude are rather well respected by the LRGP2014 model, even if the calculations give lower AITs for rich mixtures.

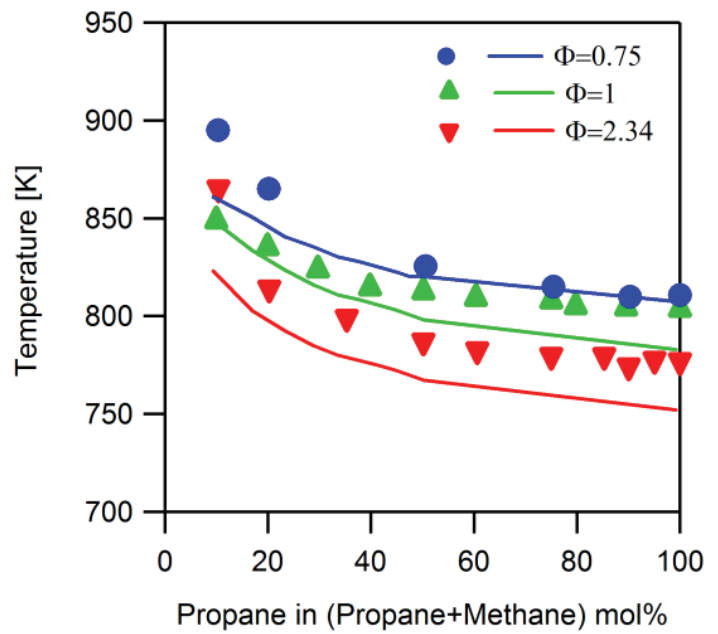

Figure 4: AIT of methane/propane/air mixtures at $\mathrm{P}=1 \mathrm{bar}$ and different equivalence ratios. Points are experimental data, lines simulations.

A further validation of the LRGP2014 model was performed against ignition delay times (AID). Auto-ignition delay times of methane/hydrogen mixture with a hydrogen mole fraction ranging from 0 to $100 \%$, were experimentally measured in a shock tube by Zhang et al. [34]. Pressure was kept at 18 bar and temperatures behind the reflected shock waves were in the range of 900 to $1750 \mathrm{~K}$ (Figure 5). Both the AID values and the trends obtained with LRGP2014 are in a good agreement with the experimental data irrespective to the fuel composition, even though the reactivity is a slightly overestimated for the lower hydrogen fractions.

Some validations were also performed with pure light alkanes. Figure 6 displays some comparisons between simulations and experimental auto-ignition delay times obtained in shock tubes for methane, ethane and $n$-butane. Figure $6 \mathrm{a}$ relates to stoichiometric mixtures of methane/oxygen/argon at 3 and 10 bar [35]. Figure $6 \mathrm{~b}$ summarizes the influence of both the equivalence ratio and the concentration of ethane under moderate pressure [36]. Figure $6 \mathrm{c}$ refers to the AID of $n$-butane at different pressures [37]. For the three fuels, the LRGP2014 model simulates fairly well the ignition-delays and the temperature dependence.

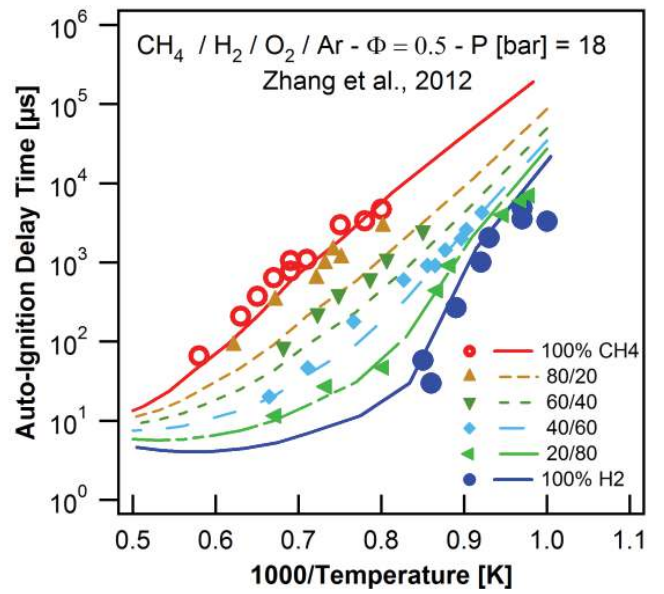

Figure 5: Auto-ignition delay times for methane/hydrogen/ oxygen/argon mixtures. Points are experimental data, lines simulations.
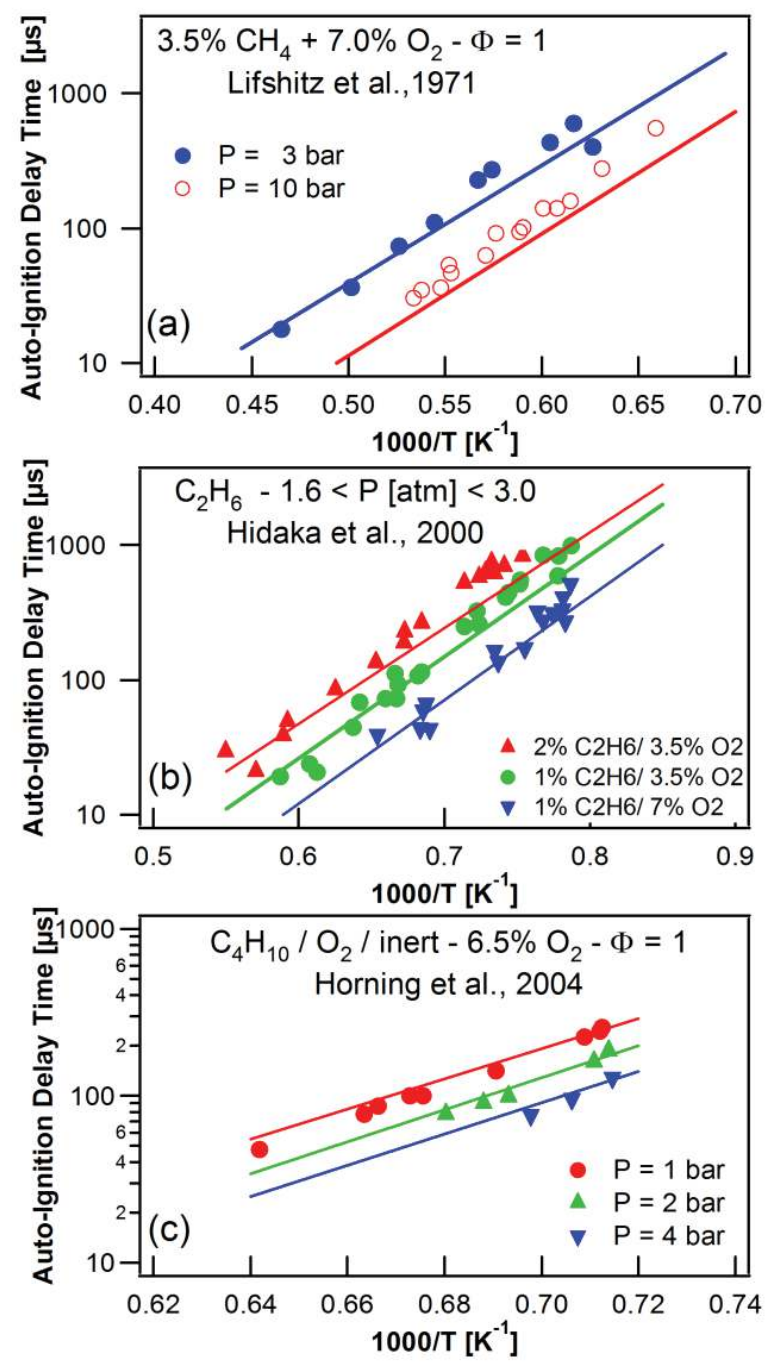

Figure 6: Auto-ignition delay times for methane (a), ethane (b), and $n$-butane (c) in shock tube. Points are experimental data, lines simulations. 
Ethane and propane are two major non-methane alkanes components of natural gas. The combustion of natural gas can be represented as that of a mixture of methane with light alkanes. Figure 7 presents the comparison between simulated results and experiments of such mixtures. Figure 7a displays the AIDs of a methane/ethane mixture, for temperature ranging between 800 and $1200 \mathrm{~K}$, with a pressure of about $20 \mathrm{~atm}$ and an equivalence ratio around 0.5 [38]. Lamoureux and Paillard [39] studied a natural gas/oxygen/argon mixture in a shock tube: figure $7 \mathrm{~b}$ shows the experimental data they found for an Algerian natural gas modeled as the following blend: $89.6 \% \mathrm{CH}_{4}+8.4 \% \mathrm{C}_{2} \mathrm{H}_{6}+1.2 \% \mathrm{C}_{3} \mathrm{H}_{8}+0.4 \% \mathrm{C}_{4} \mathrm{H}_{10}+0.4 \% \mathrm{~N}_{2}$; the equivalence ratio equaled 0.5 and the pressure was 6 bar. Here again, the LRGP2014 model successfully reproduces the sets of experiments as shown in figures $7 \mathrm{a}$ and $7 \mathrm{~b}$.
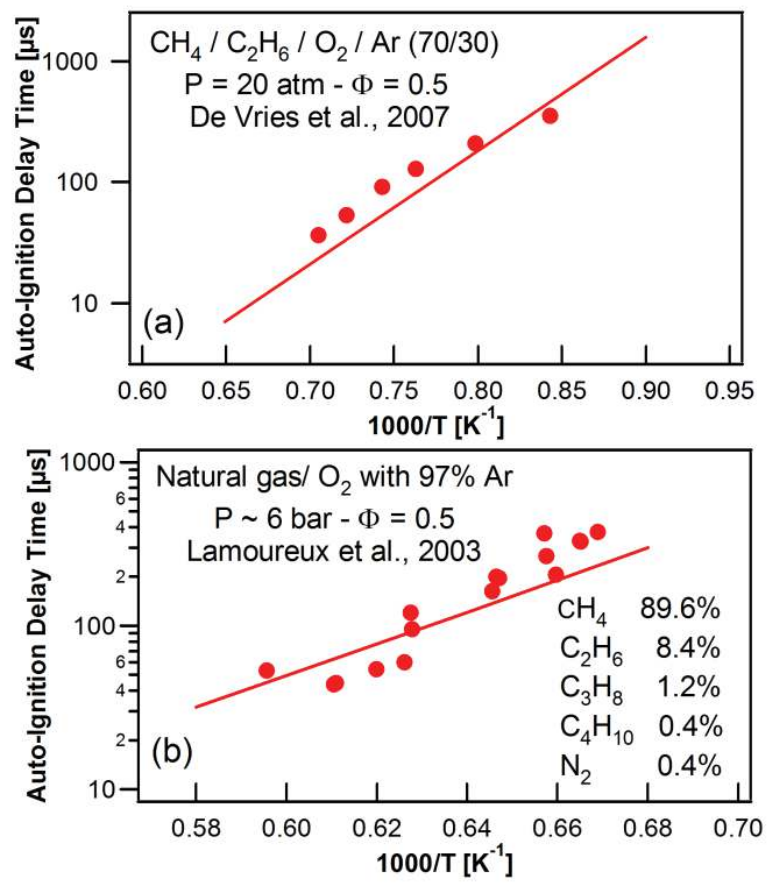

Figure 7: Auto-ignition delay times for (a), methane/ethane (b) natural gas in shock tube. Lines are simulations.

To summarize, multiple comparisons between experimental data and LRGP2014 simulations were performed, involving a large number of mixtures, equivalence ratio, pressures, temperatures and test setups. The values and the trends agree fairly well, considering the considerable experimental uncertainties in the measurement of AITs. The maximum gap between the experimental and calculated AIT data does not exceed, in most cases, $50 \mathrm{~K}$ which allows considering that the LRGP2014 model is appropriate for the prediction of AITs.

\section{USE OF THE MODEL FOR PREDICTIVE CALCULATIONS}

For safety purpose, the model has been used to predict the minimum AIT of several paradigmatic gas fuels in function of pressure and equivalence ratio. The compositions of the selected gas mixtures are shown in Table 2. Mixture B1 is methane taken as a reference. Mixture B2 represents a gas that is very rich in alkanes. Mixture B3 stands for methane enriched in hydrogen and mixture B4 represents a real natural gas typically burned in gas turbines. Mixture B5 stands for a Coke Oven Gas and mixture B6 is for a low BTU Blast Furnace Gas. In all cases, the equivalence ratio was varied from 0.2 to 4.0 and the pressure from 1 to 25 bar. In all simulations, a closed vessel with a volume of $200 \mathrm{~cm}^{3}$ was considered, with a heat transfer coefficient of $19 \mathrm{~W} \cdot \mathrm{m}^{-2} \cdot \mathrm{K}^{-1}$ at the wall and a time of 5 min for the appearance of auto-ignition. Figure 8 illustrates the results obtained with the syngas B5; they can be used in engineering studies.

Table 2. Composition of the studied fuels (\%mol.)

\begin{tabular}{|c|c|c|c|c|c|c|}
\hline & B1 & B2 & B3 & B4 & B5 & B6 \\
\hline $\mathrm{CO}$ & & & & & 7.0 & 25.0 \\
\hline $\mathrm{CO}_{2}$ & & & & 0.81 & 3.0 & 17.0 \\
\hline $\mathrm{H}_{2}$ & & & 25.0 & & 60.0 & 2.0 \\
\hline $\mathrm{N}_{2}$ & & & & 1.94 & 6.0 & 55.0 \\
\hline $\mathrm{O}_{2}$ & & & & & 1.0 & 1.0 \\
\hline $\mathrm{CH}_{4}$ & 100 & 85.0 & 75.0 & 89.15 & 21.0 & \\
\hline $\mathrm{C}_{2} \mathrm{H}_{6}$ & & & & 6.09 & 2.0 & \\
\hline $\mathrm{C}_{3} \mathrm{H}_{8}$ & & 10.0 & & 1.50 & & \\
\hline $\mathrm{C}_{4} \mathrm{H}_{10}$ & & 5.0 & & 0.40 & & \\
\hline $\mathrm{C}_{5} \mathrm{H}_{12}$ & & & & 0.07 & & \\
\hline
\end{tabular}

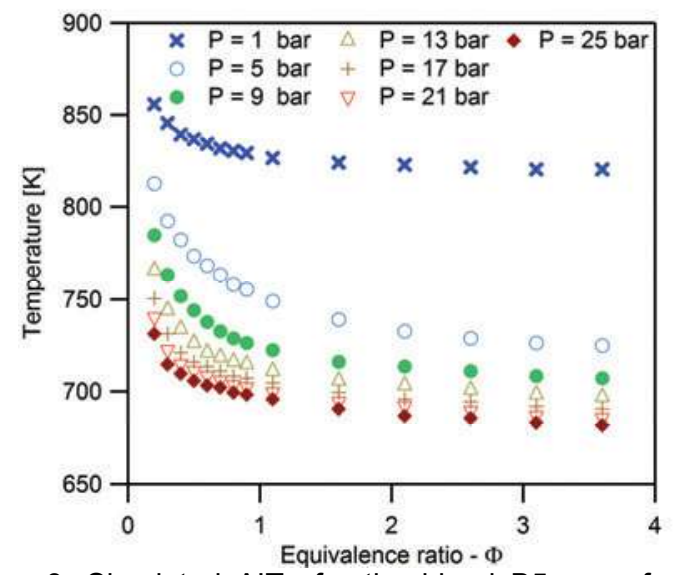

Figure 8: Simulated AITs for the blend B5 as a function of pressure and equivalence ratio.

While the detailed kinetic model enables the calculation of the AIT of individual mixtures in given conditions, it was deemed interesting to develop an analytical, multi-parameter correlation of AIT as calculated with LRGP2014, knowing that such fitting will be a pure mathematical expression without any physical meaning. To that end, a data fit by means of a mathematical expression has been performed for all mixtures. In order to derive a global expression, the different parameters were reproduced step by step. First, the variation of the AIT as a function of the equivalence ratio was represented by means of the following function:

$$
\operatorname{AIT}[K]=\alpha_{0}+\alpha_{1} \phi^{\alpha_{2}}
$$

The value of the power coefficient $\alpha_{2}$ was kept constant and equal to -0.6. Seven different expressions of $\alpha_{0}$ and $\alpha_{1}$, 
corresponding to the seven calculation pressures, were then obtained (Table 3). The second and the third steps consisted in fitting the coefficients $\alpha_{i}$ as a function of pressure and gave an analytical expression of $\alpha_{0}$ (equation 2 ) and $\alpha_{1}$ (equation 3 ):

$$
\begin{gathered}
\alpha_{0}=k_{0}+k_{1} P^{k_{2}} \\
\alpha_{1}=k_{3}+k_{4} \exp \left[-\left(\frac{\ln \left(\frac{P}{k_{5}}\right)}{k_{6}}\right)^{2}\right]
\end{gathered}
$$

where $\mathrm{P}$ is the pressure in bar, and $\mathrm{k}_{\mathrm{i}}$ parameters determined for each reacting blend. A power expression was found suitable to correlate the first parameter $\alpha_{0}$, while it was necessary to use a more complex log-normal expression to correctly fit the coefficient $\alpha_{1}$ over the entire range of conditions. Figure 9 illustrates the correlation of the values in Table 3 by these two latter expressions.

Table 3. Coefficients of the [AIT vs. $\phi]$ function for gas B5.

\begin{tabular}{cccccccc}
\hline $\mathrm{P}$ [bar] & 1 & 5 & 9 & 13 & 17 & 21 & 25 \\
\hline$\alpha_{0}$ & 811.8 & 708.1 & 689.6 & 682.4 & 678.9 & 675.9 & 673.7 \\
$\alpha_{1}$ & 16.38 & 41.66 & 35.67 & 30.30 & 25.99 & 23.68 & 21.52 \\
$\alpha_{2}$ & -0.6 & -0.6 & -0.6 & -0.6 & -0.6 & -0.6 & -0.6 \\
\hline
\end{tabular}

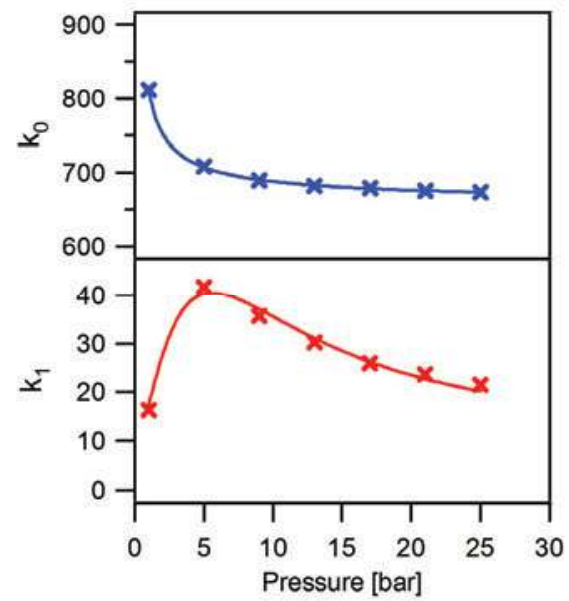

Figure 9: Fit of coefficients of the AIT vs. $\phi$ law as a function of pressure in the case of mixture B5.

Eventually, one obtains a fully analytical representation, named "the BGSF correlation", which represent the variation of the AIT as a function of the equivalence ratio and the pressure, with the AIT in Kelvin and the pressure in bar:

$$
\operatorname{AIT}[K]=k_{0}+k_{1} P^{k_{2}}+\left(k_{3}+k_{4} \exp \left[-\left(\frac{\operatorname{Ln}\left(\frac{P}{k_{5}}\right)}{k_{6}}\right)^{2}\right]\right) \phi^{-0.6}(4)
$$

Table 4 summarizes the coefficients for the blends studied. This expressions are valid for pressures from 1atm up to 25 atm, and equivalence ratios ranging from 0.4 to 4 . In the case of the gas B1 (100\% methane) a special behavior was obtained at 1 bar. Indeed, as experimentally observed at atmospheric pressure [7], the AIT of methane reaches a minimum for an equivalence ratio close to the stoichiometry, i.e. much lower than for other alkanes. For richer mixtures, the AIT of methane increases. Therefore the expressions of the $\mathrm{k}_{\mathrm{i}}$ coefficients contained in Table 4 for BN1 are valid only for pressures higher than 2 bar. Values of AIT for methane/air mixture at 1 bar have been fitted with a simple polynomial expression as follows:

$$
\begin{aligned}
& A I T_{C H_{4}, 1 \text { bar }}[K] \\
& \quad=981.5-336.3 \phi+377.4 \phi^{2}-199.1 \phi^{3} \\
& \quad+50.4 \phi^{4}-4.80 \phi^{5}
\end{aligned}
$$

\begin{tabular}{|c|c|c|c|c|}
\hline & $B 1^{b}$ & B2 & B3 & B4 \\
\hline $\mathrm{k}_{0}$ & 668.8 & -1539.8 & 641.0 & 584.2 \\
\hline $\mathrm{k}_{1}$ & 212.5 & 2320.3 & 184.8 & 221.6 \\
\hline $\mathrm{k}_{2}$ & -0.77 & -0.04 & -0.46 & -0.50 \\
\hline $\mathrm{k}_{3}$ & 24.02 & 67.06 & -8.13 & 35.36 \\
\hline $\mathrm{k}_{4}$ & 36.51 & 45.20 & 61.49 & 36.04 \\
\hline $\mathrm{k}_{5}$ & 4.90 & 15.56 & 5.39 & 4.44 \\
\hline $\mathrm{k}_{6}$ & 1.35 & 0.90 & 2.28 & 1.56 \\
\hline
\end{tabular}

Table 4. Coefficients in equation (4) for the calculation of AITs of gas mixtures, $1 \leq \mathrm{P} \leq 25$ bar, $0.4 \leq \phi \leq 4$. $^{a}$

\section{CONCLUSION}

The aim of this study was to numerically investigate the influence of process conditions on the auto-ignition temperature of different fuel/air mixtures. Although many AITs of hydrocarbon-air mixtures can be found in the literature, these values are generally determined at atmospheric pressure according to various standard test methods. Since many industrial processes operate at higher pressures, an accurate knowledge of the auto-ignition temperatures in these conditions is essential for the safe and rational operation of those processes. After a description of the key factors influencing the auto-ignition temperature, several chemical models, available in the literature, have been tested in order to find the most robust one. The low temperature and the long time scale involved in spontaneous auto-ignition events require the inclusion in the kinetic models of specific reaction channels that are negligible in usual flame conditions. A number of models that are recognized as robust in usual flame conditions, proved unreliable when extrapolated in the AIT conditions that are of interest in the present study. This robustness test led to retain the LRGP2014 model that has been developed by the LRGP laboratory, since it yielded fairly good fits through a large number of cross checks between experiments and simulations. The specific objective of this study was the prediction of the auto-ignition temperature of fuel/air mixtures depending on the pressure and the equivalence ratio. All the results have been successfully fitted by means of a BGSF correlation which enables a direct, simple analytical evaluation of the AIT for mixtures of interest in the industry, namely in gas turbine applications. 


\section{DISCLAIMER}

The information contained in this technical paper represents the best and most current information owned by the authors on the subject and is believed to be correct. However the authors and their respective organizations make no representations or warranties regarding the accuracy and will not be responsible for damages resulting from use or reliance upon this information.

\section{REFERENCES}

[1] Chemsafe, Database of evaluated safety characteristics, DECHEMA, BAM und PTB, Frankfurt/M., Germany, Update 2006

[2] Zabetakis, M.G., 1965, Flammability characteristics of combustible gases and vapours, U.S. Department of Mines, Bulletin 627.

[3] Reed R.J., 1986, North American Combustion Handbook, vol. 1: Combustion, Fuels, Stoichiometry, Heat transfer, Fluid flow, $3^{\text {rd }}$ edn., table 10.2, North America Manufacturing Company, Cleveland.

[4] Air Liquide Gas Encyclopedia, http://encyclopedia.airliquide.com/encyclopedia.asp

[5] Beerer D.J., McDonell V.G., 2008, Autoignition of Hydrogen and Air Inside a Continuous Flow Reactor With Application to Lean Premixed Combustion, Journal of Engineering for Gas Turbines and Power, 130, 051507.

[6] Steinle J.U., Franck E.U., 1995, High pressure combustion - Ignition temperatures to 1000 bar, Ber. Bunsenges. Phys. Chem. 99, 66-73.

[7] Kong, D., Eckhoff, R.K. and Alfert, F., 1995, Autoignition of $\mathrm{CH} 4 /$ air, $\mathrm{C} 3 \mathrm{H} 8 /$ air, $\mathrm{CH} 4 / \mathrm{C} 3 \mathrm{H} 8 /$ air and $\mathrm{CH} 4 / \mathrm{CO} 2 /$ air using a 11 ignition bomb, Journal of Hazardous Materials 40, 69-84.

[8] Reid I.A.B., Robinson C., Smith D.B., 1984, Spontaneous ignition of methane. Measurement and chemical model, $20^{\text {th }}$ (Int.) Symp. Combust., 1833-1843.

[9] C. Robinson and D.B. Smith, 1984, The auto-ignition temperature of methane Journal of Hazardous Materials, 8, 199-203.

[10] Caron, M., Goethals, M., De Smedt, G., Berghmans, J., Vliegen, S., Van't Oost, E. van den Aarssen, A., 1999, Pressure dependence of the auto-ignition temperature of methane/air mixtures. Journal of Hazardous Materials, 65, 233-244.

[11] Norman F., 2008, Influence of process conditions on the auto-ignition temperature of gas mixtures, PhD Thesis, Katholieke Universiteit Leuven, Belgium.

[12] Tan Y., Fotache C.G., Law C.K., 1999, Effects of NO on the ignition of Hydrogen and hydrocarbons by heated conterflowing air, Combust. Flame 119:346-355.

[13] Norman, F., Van den Schoor, F. and Verplaetsen, F. 2006, Auto-ignition and upper explosion limit of rich propaneair mixtures at elevated pressures, Journal of Hazardous Materials 137, 666-671.

[14] Van den Schoor, F., Norman, F. and Verplaetsen, F., 2006, Influence of the ignition source location on the determination of the explosion pressure at elevated initial pressures, Journal of Loss Prevention in the Process Industries 19, 459-462

[15] Chandraratna M. R., Griffiths J. F., 1994, Pressure and Concentration Dependences of the Autoignition Temperature for Normal Butane + Air Mixtures in a Closed Vessel, Combust. Flame, 99:626-634.

[16] Bartknecht, W., 1993, Explosionsschutz, Grundlagen und Anwendung, Springer, Berlin, Heidelberg, New York, 87-94.

[17] EN 14522, 2005, Determination of the minimum ignition temperature of gases and vapors, CEN.

[18] DIN 51974, 1969, Bestimmung der zündtemperatur, DIN Deutsches Institut für Normung e.V., Berlin.

[19] ASTM E 659-78, 1989, Standard test method for autoignition temperature of liquid chemicals, American Society for Testing and Materials, Philadelphia

[20] ASTM D 2883-95, 1995, Standard test method of reaction threshold temperature of liquid and solid materials, American Society for Testing and Materials, Philadelphia.

[21] Smith G. P., Golden D., Frenklach M., Moriarty N., Eiteneer B., Goldenberg M., Bowman C., Hanson R., Song S., Gardiner W., Lissianski V., et Qin Z., « GRIMech $3.0 »$, http://www.me.berkeley.edu/gri mech/.

[22] Hughes KJ, Turányi T, Clague AR, Pilling MJ., 2001, Development and testing of a comprehensive chemical mechanism for the oxidation of methane. Int $\mathrm{J}$ Chem Kinet, 33, 513-38.

[23] De Ferrières S., El Bakali A., Lefort B., Montero M., Pauwels J. F., 2008, « Experimental and numerical investigation of low-pressure laminar premixed synthetic natural gas/O2/N2 and natural gas/H2/O2/N2 flames "), Combustion and Flame, 154(3), p. 601-623.

[24] Konnov A. A., Barnes F. J., Bromly J. H., Zhu J. N., et Zhang D., 2005, " The pseudo-catalytic promotion of nitric oxide oxidation by ethane at low temperatures », Combustion and Flame, 141(3), p. 191-199.

[25] Marinov, N. M., Pitz, W. J., Westbrook, C. K., Vincitore, A. M., Castaldi, M. J., Senkan, S. M., 1998, Aromatic and polycyclic aromatic hydrocarbon formation in a laminar premixed $n$-butane flame, combustion and flame 114 192-213.

[26] N. Donato, C. Aul, E. Petersen, C. Zinner, H. Curran, G. Bourque, 2010, Ignition and Oxidation of 50/50 Butane Isomer Blends, Journal of Engineering for Gas Turbines and Power, 132, 051502

[27] Buda F., Bounaceur R., Warth V., Glaude P. A., Fournet R., et Battin-Leclerc F., 2005, « Progress toward a unified detailed kinetic model for the autoignition of alkanes from $\mathrm{C} 4$ to $\mathrm{C} 10$ between 600 and $1200 \mathrm{~K}$ », Combustion and flame, 142(1-2), p. 170-186.

[28] Tran L.-S., Glaude P.-A., Fournet R., Battin-Leclerc F., 2013, « Experimental and Modeling Study of Premixed Laminar Flames of Ethanol and Methane », Energy Fuels, 27(4), p. 2226-2245.

[29] Glaude P. A., Conraud V., Fournet R., Battin-Leclerc F., Côme G. M., Scacchi G., Dagaut P., Cathonnet M., 2002, « Modeling the Oxidation of Mixtures of Primary 
Reference Automobile Fuels », Energy Fuels, 16(5), p. 1186-1195.

[30] Biet J., Hakka M. H., Warth V., Glaude P.-A., BattinLeclerc F., 2008, « Experimental and Modeling Study of the Low-Temperature Oxidation of Large Alkanes ", Energy Fuels, 22(4), p. 2258-2269.

[31] Glaude P. A., Herbinet O., Bax S., Biet J., Warth V., Battin-Leclerc F., 2010, " Modeling of the oxidation of methyl esters-Validation for methyl hexanoate, methyl heptanoate, and methyl decanoate in a jet-stirred reactor ", Combust. Flame, 157(11), p. 2035-2050.

[32] Kee R. J., Rupley F. M., et Miller J. A., 1993, « Sandia Laboratories Report, S 89-8009B ».

[33] Pekalski, A. A., 2004, Theoretical and experimental study of explosion safety of hydrocarbons oxidation at elevated conditions, PhD thesis, UT Delft, The Netherlands.

[34] ZhangY., Jiang X., Wei L., Zhang J., Tang C., Huang Z., 2012, Experimental and modeling study on auto-ignition characteristics of methane/hydrogen blends under engine relevant pressure, international journal of hydrogen energy 37, 19168-19176.

[35] Lifshitz A., Scheller K., Burcat A., Skinner G.B., 1971, Shock-tube investigation of ignition in methane-oxygenargon mixtures Combust. Flame 16, 311.

[36] Hidaka Y., Sato K., Hoshikawa H., Nishimori T., Takahashi R., Tanaka H., Inami K., Ito N., 2000, ShockTube and modelling study of ethane pyrolysis and oxidation, Comb. Flame, 120, 245-264.

[37] Horning, D. C.; Davidson, D. F.; Hanson, R. K., 2002, A study of the high-temperature autoignition and thermal decomposition of hydrocarbons, J. Propul. Power, 18, 363-371.

[38] De Vries J., Petersen E.L., 2007, Autoignition of methane-based fuel blends under gas turbine condiotions, Proc. Comb. Inst., 31, 3163-3171.

[39] Lamoureux N., Paillard C.-E., 2003, Natural gas ignition delay times behind reflected shock waves: Application to modelling and safety, Shock Waves 13, 57-68. 